\title{
Acidentes naturais: o paradoxo entre adversidades e potencialidades na gestão urbana
}

\section{Natural disasters: the paradox between adversities and potentialities in urban management}

\author{
Clovis Ultramari \\ IURI FuKUdA HaYAKaWA*
}

\begin{abstract}
Following a theoretical discussion, we present a discussion on potentialities involving natural disasters in urban areas based on two case studies in Brazil. The case studies showed that if communities involved in adversities demonstrate a suffered conquered awareness, governmental agents still have a long way to proceed. Despite increasing research on natural disasters and their impacts, attention to their paradoxical potentialities is poor. The results presented here are to be further scrutinized, but authors already run the risk to verify the hypothesis: adverse situations may unleash potential instruments for positive urban transformations. We are aware of the paradox such idea may reveal.
\end{abstract}

Keywords: natural disaster, urban management, social vulnerabilitys.

\section{Resumo}

Este artigo busca identificar potencialidades meio a situaçôes de desastres naturais em áreas urbanas. É crescente o debate sobre acidentes naturais e seus impactos; porém é restrita à busca estratégica de instrumentos transformadores paradoxalmente disponibilizados quando dessas adversidades. A discussão teórico-referencial é seguida de estudo de caso sobre eventos adversos na Região Metropolitana de Curitiba e Região Serrana do Rio de Janeiro, Brasil. Os resultados da pesquisa ainda serão submetidos a outras realidades, porém, já se arrisca confirmar a hipótese: em situaçóes adversas, potencialidades podem ser observadas e, talvez pelo paradoxo que suscitam, são pouco apropriadas pelo gestor urbano.

Palavra-chaves: desastre natural, gestão urbana, vulnerabilidade Social.

* Pontifícia Universidade Católica do Paraná, Brasil. Correos-e: ultramari@yahoo.com e iurihaya@hotmail.com 


\section{Introdução}

Este artigo apresenta um recorte de uma pesquisa maior que busca identificar possíveis potencialidades quando de situaçóes de desastres naturais em áreas urbanas. Tal pesquisa maior é elaborada segundo sub-temáticas e com estudos de caso igualmente específicos. Desenvolvida em nível de orientaçóes de mestrado e de doutorado, assim como atividade formal de projeto com fomento institucional, a pesquisa discute possíveis novos compromissos para a gestão urbana: se, por um lado, é crescente o debate sobre acidentes naturais e seus impactos em áreas urbanas brasileiras, ainda é restrita a busca da identificação de estratégias capazes de otimizar, dentre outras coisas, os recursos disponibilizados em situaçóes de emergência. Este artigo apresenta uma discussão de caráter teórico-referencial seguida de um estudo de caso desenvolvido com a técnica de entrevistas sobre evento adverso na Região Metropolitana de Curitiba. Referencia-se também numa série de entrevistas com agentes envolvidos nos deslizamentos de terras ocorridos nos municípios da Região Serrana do Rio de Janeiro, em janeiro de $2011 .^{1}$

O enfoque que ilustra o presente artigo está vinculado a uma questão pragmática que é a de contribuir para a investigação sobre uma possível otimização nas açóes de socorro e reconstrução de cidades ou compartimentos urbanos quando de situaçóes de grandes desastres naturais. Essas ações, em ordem de grandeza e perfis diversos, são, minimamente, sugeridas por agências estrangeiras e/ou por agentes locais com diferentes capacidades, interesses e vínculos com a realidade em questão. As agências estrangeiras são aqui entendidas como instituiçóes que arregimentam esforços técnicos, operacionais e financeiros, disponibilizando-os em situaçôes humanitárias emergenciais em cidades que, em princípio, não lhes dizem respeito diretamente.

Os agentes locais, sobretudo membros da sociedade civil organizada, da prefeitura municipal e dos serviços de defesa civil, também atuam no nível do urbano em situação de emergência, agregando esforços governamentais e não-governamentais. No caso desses últimos, ressalta-se o fato de que contam com a responsabilidade de desenvolver e operar políticas públicas urbanas na área do desastre. $\mathrm{O}$ volume de esforços empreendidos por esses agentes, locais ou não, cresce em quantidade - mais recursos financeiros e mais pessoas envolvidas no socorro e no apoio à reconstrução - e em capacitação e profissionalismo: às açôes que até então se fundamentavam no desprendimento, na dedicação pessoal e no voluntarismo

\footnotetext{
${ }^{1}$ Artigo com a discussão específica sobre esse desastre frente a possíveis potencialidades que dele possam ter decorrido são encontradas em Ultramari (2013).
} 
são adicionadas iniciativas mais formais e institucionais no enfrentamento das adversidades. Com isso, altera-se mesmo aquilo que até então se entendia por solidariedade, conforme lembrado por Fensterseifer (2008:14).

O princípio da solidariedade renasce como Fênix das cinzas jurídicas da Revolução Francesa para transformar-se no novo marco jurídico-constitucional do Estado Socioambiental de Direito contemporâneo [...] buscacontinuar na edificação de uma comunidade estatal que teve o seu marco inicial com o Estado Liberal, alicerçando agora novos pilares constitucionais ajustados a nova realidade social e desafios existenciais postos no espaço histórico-temporal contemporâneo.

O presente artigo tem como pressuposto o fato de a base teórica mais recentemente utilizada para compreender as situaçóes de adversidades por acidentes naturais, seus impactos em graus e tipologias distintas segundo realidades socioeconômicas e prioridades igualmente distintas para a atuação de socorro e reconstrução, contar com um avanço significativo se comparada com compreensóes pretéritas e até então muito difundidas. Porém, este artigo também tem como pressuposto a necessidade de uma segunda mudança conceitual na discussão sobre fenômenos naturais adversos.

Em um primeiro momento, mudou-se de uma perspectiva tradicional e mais interessada em entender as causas naturais dos fenômenos adversos para uma visão mais sociológica, tratando a vulnerabilidade como uma construção social e a resiliência também como um fator resultante de determinaçôes políticas, institucionais e gerenciais (para o caso que aqui mais interessa, de gestáo urbana). De fato, conforme proposto por Rodríguez (2001); Mattedi e Butzke (2001); Marandola e Hogan (2006); Acselrad (2006); Ultramari (2006) e Ultramari e Rezende (2007), dentre outros que confirmam a recorrência dessa perspectiva interpretativa, é possível detectar essa mudança positiva a partir de uma aderência acadêmica prévia à Teoria dos Hazards para uma mais contemporânea, a Teoria dos Acidentes. Desse modo, aspectos sociais passam a ser o foco de interesse maior nas discussóes sobre situaçóes de emergência, as quais antes priorizavam o entendimento geográfico, natural e tipológico do fenômeno adverso. Com tal mudança de entendimento em níveis conceituais, adversidades naturais têm sido compreendidas cada vez menos vinculadas a simples imposiçóes da natureza e, ainda, mais distante da visão que se ocupa prioritariamente com o fenômeno e não com suas causas e consequências sociais. A síntese desse raciocínio pode ser buscada em Alexander (2003) que identifica a migração de um entendimento de desastre natural como atos de deus para um outro, onde se constrói uma tipologia de fenômenos distinguidos pelo fato de serem ou náo provocados ou enfrentados 
por açóes antrópicas: importa-se agora com o fenômeno natural, com os diferentes níveis de vulnerabilidade a ele e também com a determinação de responsabilidades. De um entendimento mais monodisciplinar - sobretudo advindo das ciências consideradas duras - parte-se para uma compreensão onde diversas perspectivas disciplinares se confundem colaborativamente. Do mesmo modo, fica consolidada a distinção entre as duas teorias mais tradicionais no debate das adversidades (Teoria dos Hazards e Teoria dos Acidentes). Enquanto a primeira se detém prioritariamente sobre os aspectos geográficos, ou seja, com a dimensão, as causas e as tipologias dos eventos naturais; a segunda, complementar à primeira, se serve da compreensão social para entender o impacto de determinados fenômenos adversos.

la classique consiste à mesurer l'endommagement potentiel des éléments exposés; la nouvelle, intégrée et complémentaire de la première, vise à cerner les conditions ou les facteurs propices aux endommagements ou influant sur la capacité de réponse à une situation de crise ${ }^{2}$ (Thouret e D'ercole, 1996).

Diferentemente de um entendimento mais generalizante, conforme proposto por Beck et al. (1992), em seus primeiros trabalhos, que substitui uma sociedade de classes por uma outra que se diferenciaria por uma generalizada submissão ao risco, priorizou-se entấo a construção do conceito de vulnerabilidade como um fenômeno social que distingue grupos e pessoas submetidas a um mesmo evento adverso. Tal compreensão sugere uma forte influência dos riscos e acidentes de forma distinta sobre áreas definidas não apenas por suas qualidades físico-ambientais, mas, sobretudo, pela heterogeneidade socioeconômica de sua população, seja em termos de responder de modo individual, associativamente ou por meio de suas representaçóes governamentais.

Mesmo desastres que parecem impactar a totalidade de cidades afetas revelam uma distinção entre situaçóes pós-desastre de suas áreas socialmente distintas. De fato, se tomarmos a ideia de injustiça revelada por Marcuse (2009), em que se observa um confinamento involuntário de grupos da população de forma segregada ou guetizada (o fenômeno da "não-liberdade") e uma alocação diferenciada dos recursos sobre o espaço (o fenômeno da distribuição injusta dos recursos). Tal cenário confirma pois o entendimento de vulnerabilidade como um fenômeno social, o qual deve caracterizar políticas públicas em diversos estágios, seja na definição de prioridades de atuação emergencial, seja no trabalho de prevenção.

\footnotetext{
2 "a clássica consiste em medir o prejuízo potencial dos elementos expostos; a nova, integrada e complementar à primeira, preocupa-se com as condiçôes ou com os fatores propícios aos prejuízos ou caracterizadores da capacidade resposta a uma situação de crise" (do original em francês).
} 
De acordo com esses novos entendimentos conceituais, a atenção do debate científico tem priorizado aspectos da redução de riscos ao desastre, identificação de possíveis mitigaçôes e aprimoramento de capacidade de resposta frente a emergências. A mudança no entendimento conceitual parece também revelar mudanças de ordem prática quando do enfrentamento a adversidades naturais por agentes sociais diversos. De fato, o empirismo permite afirmar que a gestão da emergência para situaçóes de desastre tem demonstrado, a um tempo, incremento de expertise por parte dos governos locais (sobretudo a partir da consolidação institucional de suas Defesas Civis), uma maior disposição a ações solidárias por parte da comunidade (direta ou indiretamente envolvida, local, próxima ou distante); um maior consórcio, em termos de preocupaçáo internacional, para o préstimo de socorro e uma maior disponibilidade de recursos diversos que muitas vezes podem ultrapassar a capacidade de gerência das instituiçôes que trabalham nessas situaçôes.

Destas mudanças, processuais, porém positivas, merece destaque a solidariedade, local e internacional, que cada vez mais, imediata e fortemente, responde a demandas em situaçóes de emergência em áreas que lhes são distantes, política, ambiental, econômica e culturalmente. Todavia, conforme já anunciado, tal solidariedade e voluntarismo, crescentes, parecem ainda não terem completado o necessário processo de capacitação gerencial, técnica ou administrativa.

Nearly half of French donations for victims of the 2004 Asian tsunami remained unspent 12 months ago and should be allocated to other charitable causes [...] It explained the unspent funds on the sheer volume of donations to nongovernment organizations. The problem generally met by the NGOs was not a problem of financing projects, it was a problem of using abundant, even overabundant resources [...] the World Bank said that about 60 percent of $\$ 600$ million tsunami aid it was administering for two Indonesian provinces had not been spent, adding that this rate of expenditure was fast compared to past natural disasters [...] In the case of the French Red Cross some 85 percent of the total was unused at the end of $2005^{3}$ (Jarry, 2007).

Se a primeira grande importante mudança observada no entendimento e tratamento de situaçôes adversas naturais, a qual se revelou mais

\footnotetext{
${ }^{3}$ Quase metade das doaçôes francesas para vítimas do tsunami na Ásia em 2004 se manteve sem uso por 12 meses e deveriam ser destinadas a outras causas humanitárias [...] Isto explica o volume de fundos não gastos das doaçóes das organizaçóes não-governamentais. $\mathrm{O}$ problema geralmente encontrado pelas ong não é de financiamento de projetos, mas de uso abundante, ou ainda de recursos demasiadamente abundantes [...] o Banco Mundial disse que cerca de 60 por cento dos 600 milhóes de dólares para socorro às vítimas do tsunami foram destinados a duas províncias indonésias, mas não haviam sido gastos, mesmo assim, essa taxa de utilizaçấo de despesas foi mais rápida se comparado aos de desastres naturais anteriores. [...] No caso da Cruz Vermelha francesa cerca de 85 por cento do total não foi utilizado até o final de 2005. (Do original em inglês).
} 
evidente apenas ao cabo de um longo processo, aportou relevantes aspectos investigativos, outras questôes agora merecem ser mais claramente entendidas. Tais entendimentos, sobretudo de ordem pragmática e operacional, constitui a segunda mudança da qual trata o presente artigo. A mudança necessária sugerida, e que estrutura o presente artigo, é observada em diferentes perspectivas, sempre caracterizadas pela busca de 1 . ceticismo frente a açóes de solidariedade que parecem, na maioria das vezes, isentas a críticas, e 2 . identificação de paradoxais potencialidades meio a situaçóes adversas emergentes de acidentes naturais.

Em termos do necessário ceticismo frente a questóes tradicionalmente inquestionáveis tem-se, minimamente, o esclarecimento sobre possíveis externalidades, aspectos paradoxalmente negativos das açóes de solidariedade frente a adversidades e mesmo interesses não explícitos quando de iniciativas aparentemente humanitárias. Ao discutir solidariedade em nível internacional, a já recorrentemente citada pesquisa de Djankov et al. $(2005: 3)^{4}$ revela essa mesma preocupação:

A ajuda internacional leva políticos no poder a se engajar na busca por lucros especulativos e a excluir outros grupos do processo político. Ao agirem dessa maneira, as instituiçôes políticas são prejudicadas e se tornam menos representativas e menos democráticas. [...] Nossas conclusões [atestam que] a ajuda internacional prejudica as instituiçóes políticas dos países receptores de ajuda ao reduzir suas regaras democráticas. ${ }^{5}$

Os mesmos autores citam outros estudos que adotam o mesmo enfoque em relação a doações e que podem ser aqui traduzidas como expressôes concretas de uma solidariedade internacional crescente em açốes e em volume de recursos que opera.

A literatura sobre o efeito da ajuda no desenvolvimento é alternada. Boone (1996) acredita, servindo-se de uma amostra de países em desenvolvimento, que a ajuda não tem efeito sobre investimento ou crescimento. Burnside e Dollar (2000) qualificam esse resultado ao incluir o papel das políticas públicas: ajuda tem um papel positivo no crescimento em países em desenvolvimento com boas políticas; ao mesmo tempo, não tem efeito algum em países com políticas pobres. Esse último resultado tem sido desafiado por Easterly, Levine e Roodman (2003). Easterly (2003a) aponta para o fato de que tais conclusôes sobre a pesquisa de Burnside e Dollar (2003) também são sensíveis à definição de ajuda internacional, a políticas e a resultados per capita. Easterly (2003b), por sua vez, nos traz um argumento mais forte sobre como a ajuda frequentemente fracassa em seus propósitos. ${ }^{6}$

\footnotetext{
${ }^{4}$ Nesta pesquisa, os autores discutem a ajuda para o desenvolvimento e não necessariamente a ajuda humanitária. A relação de suas conclusóes com aquilo que aqui se discute está no olhar cético frente a algo que sempre nos é apresentado como inteiramente positivo.

${ }^{5}$ Do original em inglês.

${ }^{6}$ Do original em inglês.
} 
Tais discussōes colocam pois a solidariedade à prova de olhares necessariamente céticos; porém, tal ceticismo, ao contrário de eliminar a consecução de possíveis bons resultados de tais inciativas, ajudam a pensar em açóes mais impactantes a longo prazo e eventualmente de caráter estruturador. Trata-se, entretanto de um difícil esforço de alterar antigos paradigmas. A mesma dificuldade é observada em relação às potencialidades tal qual entendidas neste artigo.

Em termos da procura, identificação e apropriação por eventuais potencialidades geradas em situaçôes adversas, tem-se, também minimamente, a ampliação e otimização da internalização de recursos, a consolidação de estruturas organizadas da sociedade, a capacitação de agentes diversos e envolvidos na prática da gestáo urbana, o debate sobre novos e mais apropriados modos de se ocupar o espaço urbano e a necessidade de se estabelecer prioridades no uso do recurso público baseadas em vulnerabilidades sociais.

Se a primeira mudança teórica a respeito do entendimento das causas e impactos decorrentes de adversidades naturais nos fez avançar para a apreensão da vulnerabilidade como um fator essencialmente social, a segunda mudança, de forma acumulativa à primeira, revela pois um necessário caráter cético e uma gerência estratégica. Ultramari (2013: 29) ao analisar esse processo, o caracteriza como um

phenomenon is part of real, concrete, but difficult-to-identify societal advances [...] In general, as expected, such changes do not occur in a linear way, but are characterized by regressions, reiterations, and marginal performances. ${ }^{7}$

Na sequência, neste contexto de avanços não-lineares para a uma segunda importante mudança de caráter conceitual e prático, apresenta-se uma discussão sobre aspectos que possam restringir valores inquestionáveis da solidariedade frente a adversidades e sobre as chamadas paradoxais potencialidades advindas dessas mesmas fenomenologias. O estudo de caso que segue diz respeito a essa segunda discussão. Antes da apresentação deste estudo, porém, faz-se uma rápida discussão sobre os dois pares de fatores que se julga importantes: 1 . ceticismo e solidariedade e 2 . potencialidades e estratégias.

${ }^{7}$ fenômeno que é parte de mudanças societárias reais, concretas e difíceis de serem identificadas [...] Em geral, como é de se esperar, tais mudanças não ocorrem de forma linear, mas são caracterizadas por regressóes, reiteraçóes e performances marginais (do original, em inglês). 


\section{Ceticismo e solidariedade}

Solidariedade é aqui entendida como açóes diversas que resultam dos chamados impulsos para o envolvimento de indivíduos, comunidade ou instituição de ajuda na gerência de emergências, em processos de reconstrução e em medidas de planejamento para a redução de risco. Tais impulsos são tradicional e mais largamente entendidos como compromissos de solidariedade; entretanto, outros fatores implicam na ajuda, na nãoajuda, no seu perfil e no montante de recursos disponibilizados que viabilizam. Apreender tais possibilidades sugere não apenas estratégias de caráter operacional, administrativo e político mas também uma atenção ao fato de que as possibilidades de se receber ajuda internacional são grandemente, e cada vez mais, influenciadas por questóes emocionais, de momento, de difusão na mídia, conforme estudo de Hutchison (2014).

De fato, limitaçóes diversas, logística, temporalidades, impactos previstos para ação, e, também, agendas e interesses institucionais não explicitados implicam em modos e prioridades distintas de solidariedade. $\mathrm{Na}$ combinação desses fenômenos causais, instituições, indivíduos e comunidade organizada se submetem ainda a uma miríade de interesses que lhes são externos, com destaque para aqueles aportados pela mídia, por redes sociais e por canais globais e multilaterais há muito institucionalizados.

Adams (1986), por exemplo, ao investigar o tempo dedicado pela televisão norte-americana para o debate de acidentes específicos na escala mundial, conclui pela sua não paridade com a gravidade dos fatos: questôes outras que não diretamente relacionadas com o acidente - étnicas, geográficas, políticas, o momento da ocorrência, sua tipologia - podem influenciar mais no interesse da população mundial, e portanto na sua disposição solidária, que propriamente o número de mortos e danos materiais.

Tem-se assim, que a verdadeira geografia da solidariedade pode ser estabelecida por parâmetros que não correspondem à gravidade da adversidade, de modo geral medida quantitativamente em danos materiais e humanos, mas sim por fatores de difícil apreensão.

Kauchakje (2012:37-38) confirma esse entendimento de solidariedade como um fenômeno que vai além (ou aquém) do sentimento de preocupação e ajuda.

o que motiva o comportamento de solidariedade nem sempre é a identificaçáo ou o compartilhamento com uma condição em si mesma, ou com uma pessoa ou um grupo social qualquer, mas, pode ser, por exemplo: a) a identificação com pessoas ou grupo determinados (quer dizer, poderia não haver solidariedade em relação a situação similar de pessoas não pertencentes ao grupo familiar, comu- 
nitário ou étnico ou, ainda, de classe social, nacionalidade ou identidades culturais e de gênero diferentes, entre outros critérios de inclusão/exclusão); b) busca por distinção e prestígio; c) autopunição ou autodefesa diante de um potencial prejuízo que a situaçáo possa causar para o próprio agente solidário ou para o grupo a que pertença; d) dever de caridade religiosa e; e) crença num estatuto legal.

Em estudo mais recente, a mesma autora lembra que tal solidariedade, em países como o Brasil, assume também um caráter estatista, por meio do "estabelecimento de direitos sociais entre os fundamentais, a provisão pública e universal no âmbito da política pública social; e formas de transferência monetária, dentre outras formas" (Kauchakje, 2013: 140). Tal regulamentação, esperadamente, não se observa meio às açôes internacionais, porém prevalece o princípio.

Assim, se, por um lado, agências de apoio (sobretudo no caso das internacionais, com maiores riscos de disparidade entre interesses locais e prioridades decididas distantemente) hoje são importantes na internalização de recursos necessários para o enfrentamento de emergências, observam-se riscos de possíveis permanências de dependência da comunidade ou cidade atingida em relação aos interesses institucionais, políticos, éticos, dentre outros, de quem ajuda. Nestas situaçóes, tem-se a fragilidade permanente induzida pela "cultura da dádiva", conforme determinada por Bourdieu (1998), Mauss (2003), e Sales (1994), ou mesmo a curse of aid $^{8}$ tal qual entendida por Djankov, et al. (2005).

Para Sales (1994) a cultura da dádiva é a expressão política da desigualdade social brasileira, substituindo os direitos básicos de cidadania e criando a noção de cidadania concedida. Similarmente, Jamur (2005: 493), ao tratar de uma solidariedade ampliada em nível internacional para o repasse de recursos, identifica três elementos por ele considerados essenciais na caracterização das condiçóes dos discursos: uma possível perda da autonomia dos Estados, submetidos às exigências de organismos internacionais financeiros; a possível inadequação da forma de intervenção do Estado a respeito do mercado como regulador econômico e social (a considerar o papel de organismos privados) e uma ameaça de ruptura dos laços sociais, pois a ajuda internacional pode desestabilizar vínculos previamente existentes.

Solidariedade não deixa de ser uma inovação social no sentido de que o indivíduo necessita dar auxílio altruísta ao próximo para o seu desenvolvimento individual. De fato, Westphal (2008) identifica dois aspectos que lhe parecem mais recorrentes acerca das teorias da solidariedade, seja

${ }^{8}$ A maldiçấo da ajuda. 
na sociologia, seja na política ou filosofia: a relação de reciprocidade entre os membros de um grupo e a base normativa presente no seu cotidiano.

Assim, ao valorizar esse segundo aspecto, reitera o necessário comprometimento do Estado com o direito da garantia do bem-estar de seus cidadãos, da sua liberdade e da sua autonomia: de um voluntarismo e desprendimento avança-se, positivamente, para uma ação de política pública comprometida. No caso da solidariedade frente a catástrofes, reitera-se assim a importância de açôes que devem ir para além do imediatismo e do passageiro: sem jamais desconsiderar a sua relevância, obriga-se a defendê-la, entendê-la e trabalha-la com maior grau de pragmatismo e de ceticismo, justapondo benefícios mais imediatos e eventuais ônus que possam perdurar.

\section{Potencialidades e estratégias}

A despeito dos grandes esforços para se entender as causas dos acidentes naturais, para desenvolver melhores açóes de atendimento a emergências e para melhor estabelecer redes de apoio, estudos para identificar as potencialidades que se acreditam emergir de situaçôes adversas ainda são incomuns. O aparente paradoxo deste entendimento pode, em parte, explicar a incipiência cientifica a seu respeito. Todavia, a distância sempre significativa entre, por exemplo, dos indicadores de severidade dos desastres e os indicadores de volume de recursos doados tem sugerido a importância de se buscar instrumentos que possam ler e apreender potencialidades menos evidentes para se internalizar recursos.

Esta ideia é reiterada por Hummell (2014) ao concluir, em estudo sobre o fluxo de recursos em nível global da ajuda internacional durante a década de 2000, que os maiores desastres não são necessariamente aqueles que mais recebem recursos; que os países mais ricos não são os maiores doadores e que há pouca linearidade na solidariedade dessas açóes. ${ }^{9}$

Tais potencialidades, ou o que pode igualmente ser nomeado de externalidades paradoxais dos acidentes naturais são, preliminarmente, detectadas quando:

- Da possibilidade de se adotar mudanças estruturais em termos de novas práticas de gestão urbana;

\footnotetext{
${ }^{9}$ No caso da Uniáo Europeia (ajuda entre os membros do bloco, apenas), esforços têm sido feitos para diminuir eventuais incongruências no repasse de recursos comuns para países com adversidades naturais. Decisão recente do Conselho do Bloco substitui a simples e dúbia situação de "grande parte da população do país estar afetada, repercussões de impacto e duradouras sobre as condiçōes de vida e de estabilidade econômica" por "perdas de 1,5\% no Produto Interno Bruto do país" como pré-requisito de elegibilidade para recebimento dos referidos recursos (Council of the European Union/Economic and Financial Affairs Council, 2014: 1, do original em inglês).
} 
- Da possibilidade de se adotar novas e mais adequadas regras e procedimentos de uso do solo urbano;

- De melhores chances de internalizar recursos disponibilizados por redes de solidariedade internacional que atuem em situações de emergência;

- Da criação de melhores condiçôes para impulsionar a economia local pela concentração de dinâmica comercial, industrial e do setor de serviços assim como a demanda incremental por máo de obra para obras de reconstrução;

- Da construção de novos laços sociais e estruturas institucionais diversas mais sólidas.

Acredita-se pois que essas potencialidades podem ser identificadas em: novas estruturas institucionais, novas formas de decisão democrática, adoção de boas práticas institucionais, lições aprendidas por meio da experiência de agentes externos envolvidos na ação de recuperação pósdesastre, novos zoneamentos de uso do solo, novas e mais adequadas legislaçôes urbanas, novas configuraçôes viárias, novas regras edilícias, mudanças em hábitos de construção arquitetônica, diferenças qualitativas na provisão de infraestruturas e serviços públicos.

Pesquisa junto às administraçóes locais da Região Serrana do estado do Rio de Janeiro ${ }^{10}$ quando dos processos de reconstrução urbana devido aos deslizamentos ocorridos na estação das chuvas em $2011^{11}$ revelam, ao mesmo tempo, uma apreensão pela situação mais fortemente revelada pelos acidentes: ocupaçôes de áreas inadequadas, desrespeito generalizado ao formulado pela legislação edilícia e de parcelamento, sujeição da população mais carente aos maiores riscos, inoperância dos diferentes níveis de governo e uma clara identificação de alteraçóes positivas. A identificação de tais alteraçôes é que se busca explicitar aqui, sempre

${ }^{10}$ Esta pesquisa é realizada com fomento do CNPq, sob coordenaçáo do primeiro autor deste artigo e intenciona determinar grandes áreas com recorrência de acidentes em nível do território nacional. No caso da Regiáo Serrana do Rio de Janeiro, procedeu-se a uma série de entrevistas com agentes locais, destacando aqueles que integram as prefeituras municipais e as agências de Defesa Civil. As questôes do questionário são: 1 . Vocês atuaram em um problema local, porém vinculados a uma instituição internacional. Esse vínculo impóe regras ou práticas que de outra maneira vocês năo adotariam? 2. Vocês trabalham em momentos de tragédia. É possível observar algum aspecto positivo que se imponha na realidade, uma vez encerrada a emergência? (ex.: novas práticas, novas leis, novos comportamentos, publicação de um problema sério, mas pouco discutido na sociedade). 3. Do ponto de vista institucional, ter se envolvido em uma calamidade que contou com exibiçáo na mídia pode ter contribuído positivamente para outras açôes ou militâncias da instituição que você representa? 4. A partir da atuação de sua instituição durante o período de emergência é possível identificar continuidades? 5 . Do ponto de vista das ideias defendidas por sua instituição, é mais fácil e mais "proveitoso" atuar durante emergências ou durante momentos de normalidade?

${ }^{11}$ Esse desastre diz respeito a minimamente nove municípios do estado e provocou a morte de quase mil pessoas. 
conscientes do ostensivo e intrínseco paradoxo que compóem tais externalidades positivas.

Antes do desastre de 2011, a Defesa Civil da cidade de Sumidouro não existia para a população em geral; atualmente, está na mira da sociedade. Isso significa que a Defesa Civil é procurada para outras coisas que a população precisa e que por ventura estejam sob a responsabilidade de outras secretarias municipais. Atualmente, se alguém tem dúvida a respeito da compra de uma casa, por exemplo, o interessado primeiro procura informação aqui para ter certeza de que está em conformidade com a lei ou não! (Benther, entrevista personal, 13 de enero, 2012).

Se alguma coisa mudou, tal fato pode ser confirmado meio à população e não nos níveis de governo. A população está agora mais receosa em ocupar áreas de risco e há uma maior consciência do problema; elas deixam suas casas quando a previsão do tempo anuncia possíveis enchentes ou deslizamento de terras. Agora, o risco é entendido pela sociedade. Em termos de governo, poucas coisas mudaram; se algo foi feito, ainda é muito tímido (Muller, entrevista personal, 20 de enero, 2012).

A consciência da população foi o maior ganho obtido a partir dos desastres de 2011. Isso ainda não é suficiente, mas não há dúvida que existe uma preocupaçáo maior por parte das pessoas que contribui para a diminuição das áreas de risco e também uma imediata saída das propriedades quando do anúncio de riscos. Se você perguntar a alguém da comunidade, não importa o quão pobre ela seja, ela saberá, por exemplo, que serviços de dragagem devem ser conduzidos. Da parte do governo, parece ainda faltar o mínimo de conhecimento para propor uma intervenção mais estrutural para reduzir riscos (Cunha, entrevista personal, 12 de enero, 2012).

De fato, a partir dos questionários aplicados junto às instituiçóes envolvidas no processo de soluçóes diversas para o período que se seguiu às cheias de 1995 na Região Metropolitana de Curitiba e na reconstrução pós-desastre de 2011, na Regiáo Serrana do Rio de Janeiro, parece haver uma concordância em relação a mudanças positivas no período que se seguiu à adversidade. Evidentemente, não foram mudanças estruturais e tampouco ocorreram de forma equânime entre os diferentes agentes da sociedade. Se houve alteração na forma como a população entende a dinâmica da ocupação urbana, as particularidades do terreno que ocupam e sobretudo o papel das agências governamentais, demonstrando níveis mais avançados de cobrança; da parte do estado, a sua absorção e resposta são lentas. $\mathrm{Na}$ busca das chamadas potencialidades estratégicas aqui discutidas, porém, parece se confirmar a ideia de que, minimamente,

Hoje, como fora no passado, grandes catástrofes constituem momentos que levam as pessoas e a sociedade a pensar sobre si mesmas e sobre seus futuros (Lima, 2008: 7). 
Em ambos, os estudos empíricos aqui utilizados como referência, os níveis de consciência por parte da população em relação a riscos existentes, ao papel do estado no encaminhamento de soluçóes e a sua inserção numa sociedade desigual eram reconhecidamente reduzidos. A despeito de se reconhecer a dificuldade de medir tal situação, o debate público trazido por essas calamidades alterou a postura das comunidades mais afetadas frente a seus representantes políticos e às instituiçôes constituídas para garantir níveis mínimos de habitabilidade na cidade. No relato das entrevistas realizadas para os dois casos, a modernização das estruturas da Defesa Civil e das secretarias de urbanismo municipais, no caso do Rio de Janeiro, e o maior diálogo entre instâncias governamentais diversas no caso da Região Metropolitana de Curitiba, são citados como exemplos de conquistas comunitárias agora capazes de se fazer ouvir.

Similarmente à pesquisa realizada para o caso dos acidentes de 2011 no estado do Rio de Janeiro, procedeu-se uma outra pesquisa, porém mais específica para os propósitos deste artigo, que busca identificar as chamadas potencialidades. No item a seguir, tem-se uma discussão sobre como intervençôes urbanas há muito considerada importante para o saneamento de uma regiâo, mas jamais contou com prioridade projetual ou financeira, teve sua realização decidida quando de uma situação de emergência.

\section{O caso da Regiáo Metropolitana de Curitiba}

Catástrofes não são evidentemente precursoras ideais da implantação de uma política urgente de atendimento às demandas básicas. É recorrente a observação de que há um já histórico reduzido comprometimento social por parte da gestão urbana brasileira. No caso da ocorrência de catástrofes, não apenas esse fato persiste, mas também fica clara uma reduzida capacidade de gerência e de apreensão estratégica de oportunidades que possam reduzir necessidades precípuas da maioria da populaçáo.

O estudo de caso descrito neste item está relacionado a situaçóes de risco ambiental em áreas urbanas vulneráveis como definidoras de inflexóes no planejamento e na gestáo urbana, assim como com o papel do planejamento urbano nas açóes de prevenção e redução de ocorrências de situaçóes de risco. Dessa forma, interessa aqui discutir o planejamento de forma dual. A primeira, tradicional, como potencializador ou mitigador de situaçóes de risco, definindo, a priori, e segundo conhecimento técnico, áreas a ocupar e com quais parâmetros. A segunda como instrumento capaz de, frente a situaçóes extremas, se atualizar e mesmo de rever paradigmas por demais estabelecidos na prática da gestáo urbana. Se a primeira forma de se entender planejamento urbano, e regional, já lhe parece ser inerente, sobretudo com o avanço da inclusão da questão 
ambiental nas suas práticas de ocupação, uso e apropriação do território, é incipiente a sua formatação pela apropriação das eventuais potencialidades que, paradoxalmente, as calamidades possam ofertar.

Para entender essa hipótese, este estudo de caso discute como, a partir de intensas chuvas e inundaçóes ocorridas em 1995 na Região Metropolitana de Curitiba (RCM), aceleraram a implantação de obras de saneamento que eram, muito preteritamente, defendidas como necessárias. Mais especificamente, discute-se aqui a grande inundaçáo ocorrida no verão de 1995 na porção leste da RCM e a decorrente construção do chamado Canal Extravasor do rio Iguaçu. ${ }^{12} \mathrm{O}$ referido canal, hoje em uso, tem por finalidade a contenção das cheias das bacias do Alto Iguaçu e do Belém, seu afluente, evitando enchentes em áreas contribuintes.

Este estudo de caso $^{13}$ está fundamentado em pesquisa documental e em pesquisa de campo. A pesquisa de campo foi consubstanciada em questionários com pessoas envolvidas no processo de decisão de aporte de recursos diante da situação emergencial. Esta é a fonte de informaçôes que mais interessa para o presente artigo. As entrevistas foram realizadas com sete profissionais / políticos - do governador do estado do Paraná ao técnico responsável pelo licenciamento ambiental - em posição de destaque decisório para a proposição, avaliação e implantação da referida obra do canal.

A inundação de 1995 provocou uma precipitação pluviométrica de $121 \mathrm{~mm}$, atingindo 16.655 pessoas e inundando 3.999 casas. Diante da dimensão do impacto, foi decretado Estado de Calamidade Pública pela prefeitura de Curitiba e Estado de Emergência na RCM pelo Governo do Paraná. Além das medidas emergenciais de socorro às vitimas, avivou-se o debate sobre a construção do referido Canal como medida urbanística estrutural e em discussão em nível de planejamento e gestão metropolitanas desde a década de 1980 .

Para a comprovação quanto à possível agilização, no nível do planejamento e da gestão, de intervenção já considerada prioritária, mesmo para períodos de precipitaçóes medianas, a pesquisa elaborou e aplicou entrevistas semi-estruturadas, composta de cinco questóes, cujo foco consistiu identificar a relação entre a tomada de decisão e a evidência do desastre. As entrevistas foram aplicadas a pessoas envolvidas diretamente no processo de defesa e de implantação do Canal Extravasor, todas com poder decisório em seus órgãos de governo, agregando-se, portanto, visões do nível

\footnotetext{
${ }^{12}$ Este canal, com extensấo de $20 \mathrm{~km}$, largura variável entre 25 a 40 metros e de 3 a 4 metros de profundidade, corre paralelo ao rio Iguaçu, o qual constitui a principal bacia de abastecimento da rmc e corta suas principais áreas urbanizadas.

${ }^{13} \mathrm{~A}$ íntegra deste estudo de caso pode ser encontrado em Hayakawa (2008).
} 
do planejar e do gerir. ${ }^{14} \mathrm{O}$ fato de as entrevistas terem sido realizadas mais de uma década após o acidente permitiu uma liberdade maior para os entrevistados, uma vez que já não integravam a equipe de governo ou posiçôes chave que poderiam sugerir restriçôes nas análises ou vínculos políticos.

A seguir, alguns extratos mais significativos dessas entrevistas.

Dada a urgência para a solução dos impactos ambientais causados pela falta de implantação desses empreendimentos, foi formada uma equipe técnica ciente do prazo restrito, que trabalhou na análise e no licenciamento ambiental desses quatro empreendimentos, de forma ágil, colocando-os como prioridade. (Piazzetta citado em Hayakawa, 2008).

Em função da emergência para a construção do canal, o trâmite de liberação do licenciamento foi agilizado, porém com as previsóes das medidas mitigadoras e compensatórias pertinentes as etapas do licenciamento. (Branco citado em Hayakawa, 2008).

Com o estudo ambiental prévio realizado e aprovado, o Canal Extravasor teve o projeto executivo acelerado e adaptado às condiçóes extremas observadas durante as enchentes de janeiro e das possíveis cheias durante o período das chuvas decorrentes do El Nino. (Hayakawa L. citado em Hayakawa, 2008).

$\mathrm{Na}$ enchente de 1995, como era uma situaçáo de emergência, com o repasse do recurso do governo Federal ao Estado foram feitos os primeiros $9 \mathrm{~km}$ do Canal Extravasor e ao Município de Curitiba fez-se a redragagem de $14 \mathrm{~km}$ do rio Iguaçu, a qual não estava prevista no orçamento. (Kluppel citado em Hayakawa, 2008).

De modo geral as entrevistas demonstram uma concordância em termos da incontestável agilização na finalização do projeto do Canal, de sua avaliação ambiental, da disponibilização de recursos para sua obra e sua construção em curto prazo. A implantação de medidas de forma acelera-

\footnotetext{
${ }^{14}$ No total, contou-se com sete técnicos em posiçăo de decisão durante o início e a avaliaçăo da obra do Canal: a) o governador do Paraná na época, arquiteto Jaime Lerner, por ter decretado Estado de Emergência na RMC e centralizado a coordenação das obras do Canal; b) o diretor-presidente da Coordenação da Regiáo Metropolitana de Curitiba, arquiteto Luiz M. Hayakawa, por presidir açóes delegadas diretamente pelo governador do Estado para o planejamento, projeto e obras do Canal; c) o Secretário Municipal de Saneamento e Obras do Município de Curitiba, engenheiro civil Nicolau Kluppel, por representar o órgão que executou a obra; $d$ ) a chefe do Departamento de Avaliação de Impacto Ambiental, do Instituto Ambiental do Paraná, engenheira florestal Themis Piazzetta, por coordenar o processo de licenciamento da obra; e) o diretor de Engenharia da Superintendência de Recursos Hídricos e Saneamento do Paraná, engenheiro civil José Scroccaro por participar do desenvolvimento e detalhamento do projeto; $f$ ) o diretor dessa mesma instituição, engenheiro civil Carlos A. Galerani também por desenvolver a parte técnica do projeto; $g$ ) a técnica integrante da equipe do Departamento de Avaliação de Impacto Ambiental do Instituto Ambiental do Paraná, socióloga Schirle M. dos R. Branco, por participar do processo participativo no licenciamento ambiental da obra.
} 
da é parte inerente de Situaçóes de Calamidade e de Estados de Emergência; o que distingue a situação aqui apresentada é fato de a obra já ser reiteradamente, técnica ambiental e socialmente, defendida em momentos de normalidade climática, porém sempre sem sucesso. A leitura das respostas dos técnicos envolvidos na confirmação da intervenção, indica mais que uma esperada agilização no nível do planejamento e da gestão urbana nas liberaçôes de recursos, a sua simples confirmação como prioridade.

Reconhece-se que, apesar de se poder identificar a confirmação e agilização na disponibilização de recursos para a obra de saneamento, a forma com que esse processo ocorreu demonstrou também - tal qual no caso dos desastres na Região Serrana do Rio de Janeiro - um baixo nível de apropriação governamental frente a outras oportunidades estratégicas que deveriam ter sido positivamente identificadas.

A realização da obra do Canal Extravasor demandou a liberação de extensas áreas constantemente sob pressão de ocupação irregular e com características ambientais que inviabilizam sua urbanização, ainda que com elevadas inversóes de recursos técnicos e financeiros. A própria enchente, ao exigir a remoção de famílias para áreas previamente estabelecidas pelo planejamento, igualmente liberou parcelas dessas áreas. Todavia, a inexistência de estratégias de ocupação territorial por parte dos governos municipais e estadual para essas áreas remanescentes, não obstou novas ocupaçóes irregulares e com densidades ainda mais altas que no estado prévio. Disso resultou o assentamento denominado Vila Audi, ${ }^{15}$ ao longo do rio Iguaçu e atualmente em custoso processo de reorganização, relocação e implantação de um parque.

Tal ocupação diminuiu a avaliação positiva que se faz do Canal; entretanto, não se desconsidera-o como paradoxal potencialidade resultante de uma adversidade natural. A crítica que persiste diz respeito à falta, por parte das autoridades envolvidas, de um juízo crítico na relação entre seu compromisso em atender a demandas básicas de habitação social, seu poder regulatório e fiscalizador na ocupação do solo urbano e o interesse e necessidade da população de baixa renda.

A pesquisa desenvolvida ao se completar exato um ano do acidente da Regiâo Serrana do Rio de Janeiro, similar na técnica investigativa e no propósito, revelou resultados similares. Neste caso deste acidente, o qual causou 915 mortes em sete cidades, as entrevistas foram realizadas junto a profissionais / políticos municipais e do governo estadual do Rio de Janeiro, técnicos dos serviços de Defesa Civil existentes na regiáo, e jor-

${ }^{15}$ Cadastro Único do Governo Federal, aplicado pela Companhia de Habitação Popular de Curitiba, 2010, revela um total de 2.554 domicílios ocupando área de fragilidade ambiental. 
nalistas. ${ }^{16}$ No caso específico da pesquisa no estado do Rio de Janeiro, também qualitativa, revelou uma situação de fortes mudanças na forma de atuação da gestáo pública e na organização comunitária. Essa mesma organização, inexistente no momento anterior ao desastre de 2011, é agora fundamental para a garantia da internalização dos recursos prometidos durante a exposição da adversidade na mídia nacional.

De fato, situaçóes de risco e calamidade aglutinam uma miríade de interesses e revelam e alteram relaçóes, compromissos, deveres e obrigaçóes. $\mathrm{O}$ caso analisado das inundaçóes na RMC indica a apropriação positiva de uma potencialidade, porém, demonstra a inépcia e descompromisso com outras. O caso analisado dos deslizamentos na Regiáo Serrana do Rio de Janeiro indica por sua vez a criação de uma consciência organizativa das comunidades impactadas e uma modernização administrativa de agências governamentais responsáveis pelo controle do uso do solo urbano e por programas de habitação popular.

Em ambos os casos, porém, mais uma vez, evidencia-se a necessidade de uma discussão, no contexto das políticas públicas urbanas, do papel dual do planejamento: não apenas como parâmetro intencional de construçáo e uso das cidades, mas também como instrumento de comprometimento explícito do estado frente a demandas sociais. Mais importante que observar e apropriar-se de potencialidades é, tal qual recorrentemente se defende, definir estrategicamente esse comprometimento.

\section{Consideraçóes finais}

Neste artigo discutiram-se mudanças no referencial teórico relativo a situações de emergência e a processos de reconstrução. A partir de uma visão mais restrita em relação à fenomenologia das adversidades naturais, o interesse cientifico avançou para uma compreensão mais complexa, multidisciplinar, apta a priorizar a prevenção e não o reparo e a vulnerabilidade social, e não o fenômeno físico-ambiental.

A partir do momento em que a consciência acerca do risco é entendido pela população atingida, facilita-se a sua participação na elaboração das políticas públicas relacionadas com o planejamento urbano de uso e ocupação do solo, assim como a compreensão do papel das agências governamentais também demonstram níveis mais avançados de cobrança da parte do estado.

\footnotetext{
${ }^{16} \mathrm{O}$ total de entrevistados foi de 25, garantindo uma amostragem mínima de formadores de decisão ou então de tomadores de decisão de 3 por município. Apesar de as mortes ocorrerem em sete municípios, as chuvas afetaram o cotidiano e desalojaram famílias em outros oito, totalizando uma regiáo afetada de quinze municípios distantes $100 \mathrm{~km}$ da cidade do Rio de Janeiro.
} 
Se tal mudança significa avanços significativos para a convivência que se indica ser cada vez mais ostensiva da sociedade urbana com adversidades naturais e acidentes, observou-se aqui a validade de outra mudança; aquela que, reconhecendo o paradoxo, se propóe a identificar recursos estratégicos quando da ocorrência de perdas sociais, econômicas e de desestabilização do tecido, tangível e intangível, urbano. Para sustentar a defesa de tal mudança, discutiram-se, ceticamente, as açóes de solidariedade, aqui entendida como compromissos de solidariedade institucional de ajuda na gerência de emergências, em processos de reconstrução e em medidas de planejamento para a redução de risco, implicando em prioridades distintas de solidariedade, e, com pragmatismo gerencial, a paradoxal existência de potencialidades em momentos de adversidades naturais.

Estar-se-ia assim frente a uma postura 1. Estratégica para identificar potencialidades no momento de adversidades e 2 . De desconfiança a fatores que, em princípio, nos são sempre positivos, como é o caso da solidariedade. $\mathrm{O}$ estudo do processo de obtenção de recursos para o projeto e obra do canal extravasador da Regiáo Metropolitana de Curitiba pode exemplificar a importância da primeira postura; o estudo dos impactos trazidos pelo acidente de 2011 no estado do Rio de Janeiro exemplifica a validade da segunda postura ao provocar sobretudo mudanças positivas na organizaçáo da comunidade local e no papel de agências do governo.

Para esse caso específico, a organização da comunidade revelou uma demanda que vai para além da ajuda emergencial. De fato, conforme demonstrado nas entrevistas, o importante já não pode se limitar ao atendimento a demandas emergenciais efetivado por meio de doaçóes em alimentos, vestuário e abrigo temporário. Formas tradicionais de solidariedade foram reiteradas como importantes, porém se mostraram insuficientes e, mais importante que isso, alertaram para a necessidade de mudanças estruturais na forma de uso e ocupaçáo do solo urbano.

A identificação desta mudança, de ordem estratégica e operacional, é visualizada como possível nos níveis do planejamento e gestão urbana. Com isso, esses dois instrumentos transformativos da cidade não apenas exerceriam um papel de prevenção e redução de ocorrências de situações de risco, mas igualmente estratégico, mais uma vez, na identificação e apropriação de eventuais potencialidades delas advindas.

Nos estudos de caso relatado neste artigo, apresentado com a intenção de discutir a necessidade de mudanças, demonstrou a existência de potencialidades meio a adversidades e sugeriu a importância de sua apreensão. Ao observar sua apreensão de forma mais contundente por parte da população, revelou porém que, em nível das políticas públicas, o estado as apropria de forma parcial, como no caso da Região Metropolitana de 
Curitiba, ou as desconsidera, como no caso da Região Serrana do Rio de Janeiro. Naquilo que diz respeito especificamente à Regiāo Serrana do Rio de Janeiro, foi revelado, por um lado, açóes de solidariedade imediatas e que satisfizeram necessidades mais emergenciais; por outro, paradoxalmente, contribuíram para reduzir o debate sobre questóes absolutamente fundamentais para que eventos como o acidente de 2011 se repitam. De fato, a mesma solidariedade que se mostrou efetiva em seus propósitos mais específicos, retardou a solução de problemas há muito considerados estruturais. Ainda que em menor dimensão, a repetição de adversidades similares em janeiro de 2012, sobre o mesmo conjunto de municípios, confirma essa conclusão.

Reconhece-se que esta pesquisa ainda requer ampliaçóes investigavas relativamente ao seu recorte espacial, temporal e mesmo de tipologia de acidentes. Todavia, nos parece possível arriscar, minimamente, sugerir a continuidade da discussão, no nível da gestão urbana, sobre o paradoxo entre adversidade e potencialidade, ceticismo e solidariedade, quando da ocorrência de acidentes naturais. Se observados os acidentes sob o ponto de vista da multiplicidade dos agentes envolvidos, a partir da sua relação com a vulnerabilidade, risco, situação social, enfrentamento e respostas das catástrofes da natureza, abre-se espaço, para avançar, para um debate de políticas públicas na forma de minimizar os acidentes naturais em curso.

\section{Referências}

Acselrad, Henri (2006), "Vulnerabilidade ambiental, processos e relações", Comunicação ao II Encontro Nacional de Produtores e Usuários de Informações Sociais, Econômicas e Territoriais, FIBGE, Rio de Janeiro, <http://www.ibcperu.org/doc/isis/11342.pdf>, 25 de janeiro de 2013.

Adams, William (1986), "Whose lives count? TV coverage of natural disasters", Journal of Communication, 36 (2), Wiley, pp. 113-122, <http://www.gwu.edu/ $\sim$ pad/202/readings/disasters.htm>, 30 de julho de 2013.

Alexander, David (2003), Terrorism, disasters, and security, University of Wisconsin, Madison.

Beck, Ulrich, Anthony Giddens e Scott Lash (1992), Reflexive modernisation, Polity Press, Cambridge. 
Bourdieu, Pierre (1998), Escritos de Educaçāo, Vozes, Petrópolis.

Council of the European Union/Economic and Financial Affairs Council (2014), "Council adopts new rules for Eu solidarity fund", Council of European Council Press, Bruxelas.

Djankov, Simeon, Jose G. Montalvo y Marta Reynal-Querol (2005), “The curse of aid: the World Bank", working paper 45254, World Bank, $<$ http://www.econ.upf.edu/docs/papers/downloads/870.pdf >, 23 de janeiro de 2012 .

Fensterseifer, Tiago (2008), "Estado socioambiental de direito e o princípio da solidariedade como seu marco jurídico-constitucional", Jus Navigandi, 13 (1669), <http://jus.com.br/revista/texto/10887>, 22 de julho de 2012.

Hayakawa, Fukuda Iuri (2008), "Situaçôes de risco ambiental como definidoras de nflexões no planejamento e na gestão urbana um estudo na cidade de Curitiba-Paraná", dissertação de mestrado defendida junto ao Programa de Pós-graduação em Gestão Urbana, Pontifícia Universidade Católica do Paraná, Curitiba.

Hummell, Beatriz Maria de Loyola (2014), Das Geografias da solidariedade: inequidades no direcionamento de recursos internacionais em momentos pós-desastres naturais na década de 2000, tese de doutoramento defendida junto ao Programa de Pós-graduação em Gestão Urbana da Pontifícia Universidade Católica do Paraná, Curitiba.

Hutchison, Emma (2014), "A global politics of pity? Disaster imagery and the emotional construction of solidarity after the 2004 asian tsunami”, International Political Sociology, 8 (1), International Studies Associati, Tucson, pp. 1-19.

Jamur, Marilena (2005), "Solidariedade: uma noção tensionada entre o privado e o público", Revista RAP, 39 (3), Fundação Getúlio Vargas, Rio de Janeiro, pp. 471-504.

Jarry, Emmanuel (2007), "French watchdog says reallocate excess tsunami AID”, Reuters, Paris, <http://uk.reuters.com/article/2007/ 
01/03/uk-france-tsunami-idUKL0314404320070103>, 21 de maio de 2014 .

Kauchakje, Samira (2012), "Valores de solidariedade e norma jurídica", dissertação de mestrado, Universidade Federal do Paraná, Curitiba, <www.humanas.ufpr.br/.../2012/05/dissertação-samirakauchakje-1.pdf>, 12 de julho de 2012.

Kauchakje, Samira (2013), "Instituiçóes, cultura e difusão de políticas: modelagem internacional de políticas públicas brasileiras para redução da pobreza", Ciências Sociais Unisinos, 49, Unisinos, Porto Alegre, pp. 135-144.

Lima, Maria Luísa Pedroso de (2008), “Tragédia, risco e controle: uma releitura psicossocial dos testamentos de 1755", Revista Análise Social, XLIII, Instituto de Ciências Sociais da Universidade de Lisboa, Lisboa, pp. 7-28.

Mattedi, Antônio, Cristina Butzke (2001), "A relação entre o social e o natural nas abordagens de hazards e de desastres", Revista Ambiente \& Sociedade, 9, Unicamp, Campinas, pp. 1-22.

Marandola jr., Eduardo e Daniel Joseph Hogan (2006), "As dimensōes da vulnerabilidade”, São Paulo em Perspectiva, 20 (1), Fundação Seade, São Paulo, pp. 33-43, <http://www.seade.gov.br>, 13 de junho de 2013.

Marcuse, Peter (2009), "Spatial justice: derivative but causal of social injustice”, Justice spatiale/spatial justice, 1, Columbia University, New York, <http://www.jssj.org>, 21 de maio de 2014.

Mauss, Marcel (2003), Sociologia e antropologia, Cosac \& Naify, São Paulo.

Rodríguez, Jorge (2001), "Vulnerabilidad demográfica: una faceta de las desventajas sociales", Cepal. Serie Población y Desarrollo, 5, Cepal, Santiago del Chile.

Sales, Teresa (1994) "Raízes da desigualdade social na cultura política brasileira”, Revista Brasileira de Ciências Sociais, 25, Associação 
Nacional de Pós-Graduação e Pesquisa em Ciências Sociais (Anpocs), São Paulo, pp. 26-37.

Thouret, Jean-Claude e Robert D’ercole (1996), "Vulnérabilité aux risques naturels en milieu urbain: effets, facteurs et réponses sociales", Cahiers Sciences Humaines, 32 (2), Les Editions de l'Aube, Paris, pp. 407-422, <http://horizon.documentation.ird.fr/exldoc/ pleins_textes/pleins_textes_4/sci_hum/010006241.pdf>, 21 de maio de 2014.

Ultramari, Clovis (2006), "Vulnerabilidades, resiliência e crises cumulativas urbanas”, São Paulo em Perspectiva, 20 (1), Fundação SEADE, São Paulo, pp. 109-122, <http://www.seade.gov.br/ produtos/spp/v20n01/v20n01_08.pdf>, 21 de maio 2014.

Ultramari, Clovis e Denis Rezende (2007), "Urban resilience and slow motion disasters", City \& Time, 2 (3), Centro de Estudos Avançados da Conservação Integrada, Olinda, pp. 47-64, <http://www. ct.cecibr.org>, 21 de maio 2014.

Ultramari, Clovis (2013), "910; 7; 365: an essay on urban potentialties", Urban Land Policy, 4, Centre for Rural Health and Community Development-University of South Australia, Cambridge, pp. $125-133$.

Westphal, Vera Herweg (2008), "Diferentes matizes da ideia de solidariedade”, Revista Katálysis, 11 (1), Universidade Federal de Santa Catarina, Florianópolis, pp. 43-52.

Aceptado: 14 de novembro de 2012.

Reenviado: 7 de julho de 2013. Aceptado: 25 de setembro de 2013.

Clovis Ultramari. Brasileiro. Arquiteto e doutor em meio ambiente e desenvolvimento urbano. É professor em gestão urbana da Pontifícia Universidade Católica do Paraná e professor colaborador no Programa de Pós-graduação em Meio Ambiente e Desenvolvimento da Universidade Federal do Paraná. É pesquisador Produtividade pelo Conselho Nacional de Desenvolvimento Científico e Tecnológico (CNPq). Sua linha de pesquisa atual diz respeito ao estudo dos Grandes Projetos Urbanos e seus 
impactos físico-territoriais das cidades, dos Grandes Acidentes Naturais e a geração de oportunidades a partir de tais adversidades. Complementarmente, tem iniciado uma nova temática de interesse que é a da Migraçáo das Ideias no estudo do urbano: suas origens e condiçóes de replicabilidade. Entre suas publicaçóes vale destacar: "La recurrencia de las ideas en el estudio de planeamiento urbano en Brasil", Ciudad y Territorio, Estudios Territoriales, XLV, série 175, pp. 147-162 (2013); “Um acidente e duas perspectivas analíticas: o grande terremoto de Lisboa e os estudos de Edward Paice e de Rui Tavares", Revista EURE, 39 (118), Pontificia Univeridad Católica de Chile, Santiago de Chile, pp. 269-272 (2014); e "910; 7; 365 an essay on urban potentialties", Land Use Policy, journal citation Report, 34, pp. 125-133 (2013); em coautoria, "Sobre mudanças e continuidades na gestão urbana brasileira”, Revista Mercator, 1, Universidade Federale do Ceará, Fortaleza, pp. 73-88 (2012).

Iuri Fukuda Hayakawa. Brasileira. Arquiteta, mestre e doutora em gestão urbana pelo Programa de Pós-graduação em Gestão Urbana da Pontifícia Universidade Católica do Paraná. Integra o quadro de profissionais do Instituto de Pesquisa e Planejamento Urbano de Curitiba (IPPUC). Sua linha de investigação atual é a da sustentabilidade urbana; impactos de acidentes naturais e açóes de recuperação. Suas publicaçóes mais recentes são: "Planeación urbana en Curitiba", Revista Quivera, 1, Universidad Autónoma del Estado de México, Toluca, pp. 52-69 (2010); "Situação de risco como definidoras de inflexôes no planejamento e na gestão urbana: um estudo em Curitiba”, Anais do XVI Encontro Nacional de Estudos Populacionais /ABEP, 29 de setembro a 3 de outubro de 2008, Caxambu. 